\title{
Cattle as dispersers of hound's-tongue on rangeland in southeastern British Columbia
}

\author{
ROSEMARIE DE CLERCK-FLOATE
}

The author is a research scientist in classical weed biocontrol, Agriculture and Agri-Food Canada, Research Centre, Lethbridge, Alberta, TIJ 4B1, Canada.

\begin{abstract}
Hound's-tongue (Cynoglossum officinale $\mathrm{L}$. ) is a noxious weed on forested range of western North America (N.A.), which produces barbed nutlets (burrs) that attach to animals. There is anecdotal evidence that cattle are important dispersers of hound's-tongue in N.A., although European studies suggest animal dispersal of hound's-tongue burrs is minimal. The objectives of this research were to examine the role of cattle as hound'stongue dispersers, and to develop a method of estimating hound's-tongue burr and plant density on rangeland that may be useful to researchers and range managers. To determine the movement of burrs onto cattle, the number of burrs on marked stalks, before and after grazing, were counted. In 1993 and 1994, about $65 \%$ of the burrs stalk ${ }^{-1}$ were picked up by grazing cattle, whereas, only $14 \%$ of the burrs stalk ${ }^{-1}$ were lost in a paddock ungrazed by cattle in 1994. Individual cows were monitored for burr gains and losses during monthly moves between paddocks by photographing their faces, and counting the burrs face ${ }^{-1}$ from projected slides. Cattle also were photographed every 2 weeks while in-situ on paddocks. Within 2 to 4 weeks, cows acquired and then lost burrs as they moved within and hetween paddocks. These experiments suggest that cattle are major dispersers of hound's-tongue on rangelands. There was a positive, linear relationship $\left(R^{2}=0.77 ; p<0.001, N=13\right)$ between the mean number of burrs face $^{-1}$ and the number of burr stalks ha-1 of paddock. $A$ relationship between the percent of photographed cattle with burrs and stalk density was best described by a hyperbolic model $\left(R^{2}=0.83\right)$. With refinement, these relationships between burrs on cattle and hound's-tongue density on paddocks may be useful in monitoring hound's-tongue populations.
\end{abstract}

Key Words: adhesive fruits, burrs, monitoring weed populations, noxious range weed, seed dispersal, weed biocontrol

Hound's-tongue (Cynoglossum officinale L.) is a noxious rangeland weed in western Canada and United States that was introduced to our continent from Eurasia (Scoggan 1978, Upadhyaya et al. 1988). It is particularly abundant in the Interior

Research was funded in part by an Energy, Research and Development grant (1992-94) and a grant from the B.C. Cattlemen's Association/B.C. Greenplan (1994-95) The author wishes to thank her past and present staff of Mark Bader, Tracey Bolseng, Darren Bruhjell, Tracy Dickinson, Geoff Hutchinson, Jack Kramer, Sophie Verzosa, Jennifer Walker, and Rick Weste for all the tedious stalk and burr counts. Thanks also goes to the Larson family for use of their cattle. The critical reviews of J. Moyer, W. Willms, and K. Floate are greatly appreciated, as are the graphics of S. Torgunrud, and statistical advice given by $\mathbf{T}$. Danielson.

Manuscript accepted 2 Jul. 1996
Douglas Fir and Ponderosa Pine-Bunchgrass biogeoclimatic zones of British Columbia (B.C.) (Upadhyaya et al. 1988), where cattlemen consider hound's-tongue second only to the knapweeds as a priority for control (Upadhyaya and Cranston 1991). Hound's-tongue is a concern because it hinders the establishment of forage on newly-created pastures, and its barbed seeds or burrs attach to cattle, causing irritation and potential market losses (Upadhyaya and Cranston 1991). Hound's-tongue also is toxic to livestock (Knight et al. 1984, Baker et al. 1989). Chemical and cultural controls are being used to a limited degree in British Columbia (Upadhyaya and Cranston 1991). Several European insects that feed on hound's-tongue are being tested as potential biocontrol agents, but have yet to be approved for release in North America.

Detailed studies on the ecology of hound's-tongue are needed to enhance the likelihood of its successful control, but such studies have only been done on European populations of this weed. In the Netherlands, hound's-tongue has been described as a biennial or short-lived perennial that depends on both the continual creation of disturbed habitats and the dispersal of its seed to these habitats for either population maintenance or growth (Van der Meijden et al. 1992). However, large-scale disturbances and the dispersal of hound's-tongue burrs beyond a few metres were rare in English and Dutch studies of hound's-tongue ecology (Boorman and Fuller 1984, Van der Meijden et al. 1992). Furthermore, the largest animals thought responsible for burr dispersal were rabbits (De Jong and Klinkhamer 1988), and there were doubts as to their efficacy as dispersers (Boorman and Fuller 1984). It is likely the success of hound's-tongue on the forested rangelands of North America is due to ample disturbed habitats caused by logging and other man-related activities, and the availability of large dispersal agents such as cattle. However, the role of cattle and/or wildlife in the dispersal of hound'stongue is largely anecdotal.

The objectives of this study were: 1 ) to examine the role of cattle in dispersing hound's-tongue on forested rangeland, and 2) to test the relationship between the number of burrs on cattle and the density of hound's-tongue burr stalks on paddocks. If a significant relationship is found to exist, surveys of hurrs on cattle would be useful to range managers attempting to predict the spread and increase of hound's-tongue, or to researchers monitoring the impact of control methods. 


\section{Materials and Methods}

\section{Study Area}

The study was conducted on 3 contiguous range units in the Cranbrook Forest District, British Columbia. Each range unit is divided into 5 to 6 fenced paddocks, 195 to 660 ha in area, and cattle are rotated on a monthly basis between paddocks within each range unit from May to September/October. All paddocks were within the Interior Douglas Fir biogeoclimatic zone.

Hound's-tongue infestations ranged from low to high among the paddocks. The majority of plants were situated in patches of less than 100 to several thousand individuals on logged areas that ranged from 1 to 15 ha in size. Individual hound's-tongue plants typically produce from 1 to 8 flower stalks, which are $30-120 \mathrm{~cm}$ high (Upadhyaya et al. 1988) and determinate in growth. Each stalk is capable of producing several hundred hound's-tongue seeds or burrs, which ripen near-concurrently in June or July. In B.C., the majority of ripe burrs remain on stalks until detached by passing animals.

\section{Role of Cattle in Hound's-tongue Seed Dispersal}

Two sets of experiments were conducted to determine the role of cattle in moving hound's-tongue burrs among paddocks. One set examined the movement of burrs onto cattle from hound'stongue plants, while the other examined the gains and losses of burrs from cattle over time.

The study of burr movement onto cattle took place in 1993 and 1994, on 2 separate range units, respectively, where hound'stongue burrs had recently ripened on stalks. Before cattle were released in 1993, 60 hound's-tongue stalks were randomly chosen and tagged within a $100 \mathrm{~m}$ radius on a paddock and the total number of burrs stalk ${ }^{-1}$ were counted. Within 1 week, cattle were allowed to graze the paddock. Six weeks later, after cattle had ranged throughout the paddock, a second count of burrs was made for the stalks that could be relocated (i.e., 47 stalks). Signs of cattle disturbance, such as cropping of grass, fresh hoof prints, and manure, were noted. Since deer and elk also occurred in the area, a control paddock was added to the experiment in 1994. A logged area with hound's-tongue was chosen that spanned 2 paddocks on a range unit. Whereas the paddock on 1 side of the fence was grazed by cattle, the control paddock was ungrazed. Fifty hound's-tongue burr stalks were randomly chosen within a $100 \mathrm{~m}$ radius on each side of the fence separating the 2 paddocks. These were tagged and the number of burrs stalk ${ }^{-1}$ were counted before cattle were released in the cattle treatment paddock. Burrs were counted 4 weeks later on those stalks that could be relocated (i.e., 44 stalks on grazed paddock and 50 on control paddock). Fresh signs of cattle and deer/elk were noted for both paddocks during the second visit. A paired T-test was used on the 1993 data to detect significant differences in the mean number of burrs stalk $^{-1}$ before and after grazing. The 1994 data were analysed using a repeated measures ANOVA with treatment (i.e., control versus grazed paddock) as a grouping factor. Post hoc contrasts of means were conducted on before and after grazing data using univariate repeated measures F-tests (Systat 1992). Stalks that could not be relocated for the second count were eliminated from the data sets.
To determine the fate of burrs that were attached to cattle, gains and losses of burrs were monitored on individual animals from 1 range unit. In 1992,52 to 143 cows were photographed monthly from June to September using a $35 \mathrm{~mm}$ camera fitted with a 100-300 mm telephoto zoom lens. Cattle were photographed when they were moved between paddocks during the normal rotation schedule. Photographs were frontal views of the cow face, and included the forehead, nose, and the forward-pointing surface of both ears. Photographic slides were projected, and the number of visible burrs face ${ }^{-1}$ were counted. The face was used as a sample unit because it is a good indicator of when cattle have been grazing in hound's-tongue patches, and the facial view provides identification in the form of an ear tag number. Hence, the same animals could be followed in successive photo sessions. By random chance, a total of 26 animals wcrc photographed consecutively each month from June to September. Differences in the mean number of burrs face ${ }^{-1}$ among months were detected using a one-way repeated measures ANOVA, followed by univariate repeated measures F-tests to compare consecutive months (Systat 1992).

In 1994,31 to 70 animals from a herd were randomly photographed every 2 weeks while on each of 2 different paddocks that were consecutive in the rotation schedule (Wapiti Lake and Horseshoe). These animals were photographed in situ on the paddocks and not during round-up. To detect significant differences in mean burr numbers face ${ }^{-1}$, a two-way ANOVA was conducted, with paddock and photography period as grouping factors. This was followed by Tukey HSD multiple comparisons (Systat 1992) to detect pairwise differences in means.

\section{Hound's-tongue Density and Burr Numbers on Cattle}

The relationship between hound's-tongue stalk density on paddocks and the number of burrs on cattle faces was studied from 1992 to 1994 , on the 3 contiguous range units mentioned previously (see Study Area). In total, 13 photography sessions of cattle were conducted, involving paddocks with a wide range in hound's-tongue density. None of the paddocks had been previously grazed in the rotation schedules. In 9 cases, the cattle were photographed in a holding corral after being removed from a paddock where they had grazed for 3 to 4 weeks. In 4 cases the cattle were photographed while still in the paddock. As many cows as possible were photographed each time (i.e., 33 to 149 depending on the size of the herd), and an average number of burrs face ${ }^{-1}$ paddock $^{-1}$ was determined from projected slides. The number of hound's-tongue stalks paddock ${ }^{-1}$ was estimated by thoroughly searching disturbed areas and counting all stalks. The count was expected to be a close approximation of the total number of stalks in each paddock, because hound's-tongue only grows on disturbed areas. To standardize for differences in paddock size, the number of counted burr stalks ha ${ }^{-1}$ was calculated for each paddock. The relationship between the mean number of burrs face ${ }^{-1}$ of cows that had been grazing in hound's-tongue infested paddocks and the number of burr stalks $\mathrm{ha}^{-1}$ was described with a regression equation. The percent of photographed cattle with burrs also was related to the number of stalks ha ${ }^{-1}$ using a non-linear regression program (Pcnonlin, 1992). 
Results

\section{Role of Cattle in Hound's-tongue Seed Dispersal}

Hound's-tongue burrs were reduced on stalks hy cattle activity (Fig. 1). In 1993, an average loss of $226.7 \pm 6.7$ (SE) burrs stalk ${ }^{-1}$ was noted after cattle had grazed the paddock $(d f=46, t=13.60$, $\mathrm{p}<0.001$; before vs. after cattle). This represented a $65 \%$ reduction in burrs. Only 1 out of the 47 tagged stalks (2\%) that were relocated had not lost burrs. In 1994, there was a significant effect of both treatment $\left(\mathrm{F}_{1,92}=56.51, \mathrm{p}<0.001\right.$; grazed vs. control) and time $\left(F_{1,92}=110.03, p<0.001\right.$; before vs. after cattle) on burr losses from stalks (Fig. 1). On the paddock where cattle had grazed, $140.1 \pm 14.0$ burrs stalk $^{-1}$ were removed, representing a loss of $67 \%$. Only $52.9 \pm 11.8$ burrs stalk $^{-1}$, or $14 \%$, were lost from the hound's-tongue stalks in the control paddock where cattle were absent (Fig. 1). In the control paddock, 36\% of the stalks had retained all burrs, while in the grazed paddock, only $2 \%$ of the tagged stalks had retained all burrs.

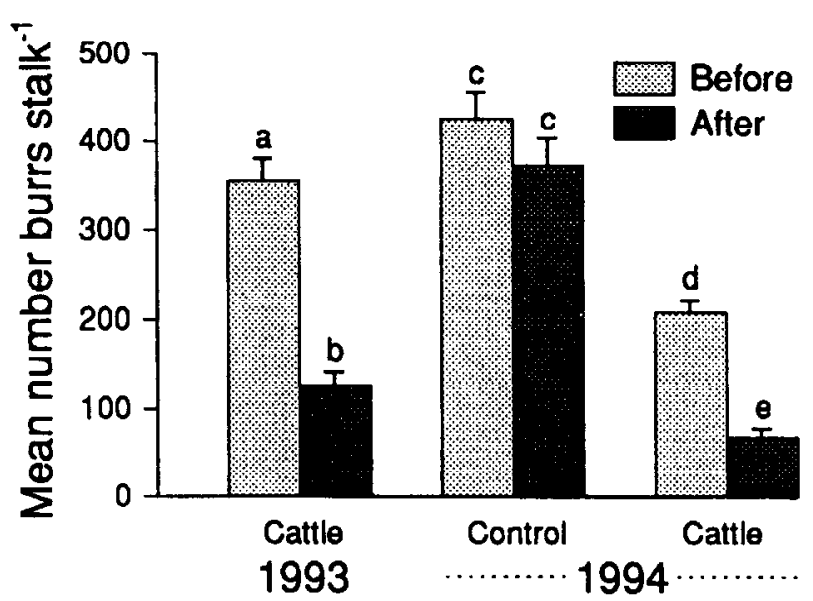

Fig. 1. Burr counts on tagged stalks before and after a cattle treatment in 1993 on a paddock where cattle had grazed, and in 1994 on a paddock where cattle had grazed, and a paddock where cattle were excluded (control). Vertical lines indicate SE of the mean. Paired bars with different letters are significantly different at $\mathbf{p}<0.05$.

When the same cows were photographed repeatedly from June to September, it was evident that they were gaining and losing burrs on a monthly basis (Fig. 2). For instance, 73\% (19/26) of the cattle photographed consecutively had gained burrs on their faces between June and July, and of these, 89\% (17/19) had lost all of their facial burrs by August. The burr losses ranged from 1 to 202 burrs face ${ }^{-1}$ (Fig. 2). Between August and September, $46 \%$ (12/26) of the cattle showed gains that ranged from 1 to 93 burrs, $12 \%(3 / 26)$ showed losses ranging from 10 to 23 , and the remaining $42 \%$ (11/26) had no facial burrs on both dates. Out of the 26 cattle photographed consecutively, 3 showed no gains across all photography dates. Mean changes in burr numbers were significant among months $\left(F_{3,75}=5.49\right.$, $\mathrm{p}=0.002$; Fig. 2$)$.

Calle photographed 2 weeks apart on 2 consecutive paddocks in a rotation, demonstrated slight fluctuations in burrs over the short-term (Fig. 3). There was no significant difference in the

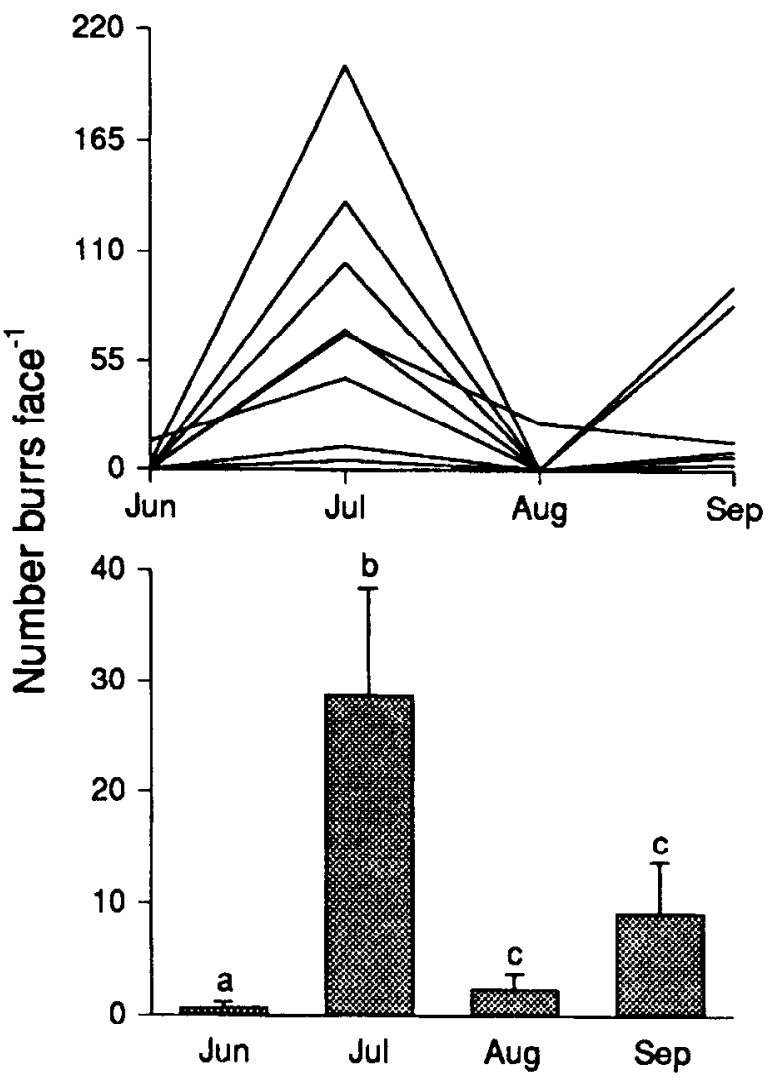

Fig. 2. Burr gains and losses on the faces of cattle photographed consecutively during monthly moves between paddocks. Top: Total number of burrs on the faces of 10 individual cows ( 1 curve cow $\left.{ }^{-1}\right)$ purposely chosen to depict the range in monthly changes which occurred. Bottom: Mean number of burrs face $e^{-1}$ for all 26 cows photographed consecutively. Vertical lines indicate SE of the mean. Any 2 consecutive bars with different letters are significantly different at $\mathbf{p}<0.05$.

mean number of burrs face ${ }^{-1}$ between photography sessions on either paddock $\left(\mathrm{F}_{1,174}=0.02, \mathrm{p}=0.89\right)$. However, there were differences in burr accumulation between paddocks $\left(F_{1,174}=4.34\right.$, $\mathrm{p}=0.04$ ).

\section{Hound's-tongue Density and Burr Accumulation on Cattle}

There was a significant, positive relationship between the mean number of burrs face ${ }^{-1}$ and the number of hound's-tongue stalks on grazed paddocks (Fig. 4). The correlation coefficient was larger when those cattle photographed in situ in paddocks were removed from the regression (Fig. 4). However, inclusion of these data points also produced a significant relationship.

The relationship between percent of photographed cattle with burrs on their faces and the number of stalks ha ${ }^{-1}$ of paddock was best described by a non-linear model of the form; $f(x)=a x / b+x$ (i.e., a hyperbolic curve; Fig. 5). The percent of photographed cattle with burrs is " $\mathrm{f}(\mathrm{x})$, and " $\mathrm{x}$ " is the density of burr stalks ha- $\mathrm{A}^{-1}$ There are 2 estimated parameters in the equation, " $a$ " and " $b$ ", which respectively represent the maximum percentage of cattle within a herd that may acquire burrs, and the stalk density at which $50 \%$ of the cattle in a herd acquire burrs. In fitting a curve to the data, the program Pcnonlin (1992) estimated $a=99.3$ and $b=11.0$. 


\section{Discussion}

The results of the present study indicate that cattle are important dispersers of hound's-tongue seed. They are not only efficient in picking up ripe burrs from standing hound's-tongue stalks (Fig. 1), but within a relatively short period can lose accumulated burrs while in the same or a different paddock (Figs. 2 and 3). Burrs adhere to cattle that are grazing or walking among standing hound's-tongue stalks on logged areas and along logging/range roads. The mature burrs can attach to any part of the cow's body, but tend to be concentrated on the head, chest, and underside of animals. Burrs probably drop from cattle as they pass through underbrush, and when they rub against each other or objects such as trees, rocks, or posts. The latter behavior was commonly observed and, not surprisingly, hound's-tongue plants often are found ringing favorite cattle rubbing areas (pers. obs.).

Sequential photographs of cows document that cattle can quickly remove a large percentage of the burrs gained. Some cows had about $\mathbf{5 0}$ to $\mathbf{2 0 0}$ burrs on their faces during the July photography session, but no burrs in August after a stay in a paddock relatively clean of hound's-tongue (Fig. 2). Although these data reflect burr gains and losses on 1 part of the cow's body, they serve to illustrate the potential for large numbers of burrs to be carried to new areas by cattle. The fruits of hound's-tongue are covered in short barbed prickles (Upadhyaya and Cranston 1991), and do not seem to adhere as tightly to cattle hair as the burrs of some other plants, such as burdock (Arctium minus (Hill) Bernh.). Only if the hound's-tongue burrs become matted in the long hairs of the ears, forehead, or tail, is long-term adherence expected.

Despite the short-term adherence of burrs to cattle, they are capable of long-distance dispersal of burrs. Given that the individual paddocks under study were up to 660 ha in area, cattle are capable of moving burrs much further than 1 to 5 meters, which was the typical dispersal range of hound's-tongue seed in the Netherlands and England (Van Leeuwen and Van Breemen 1980,

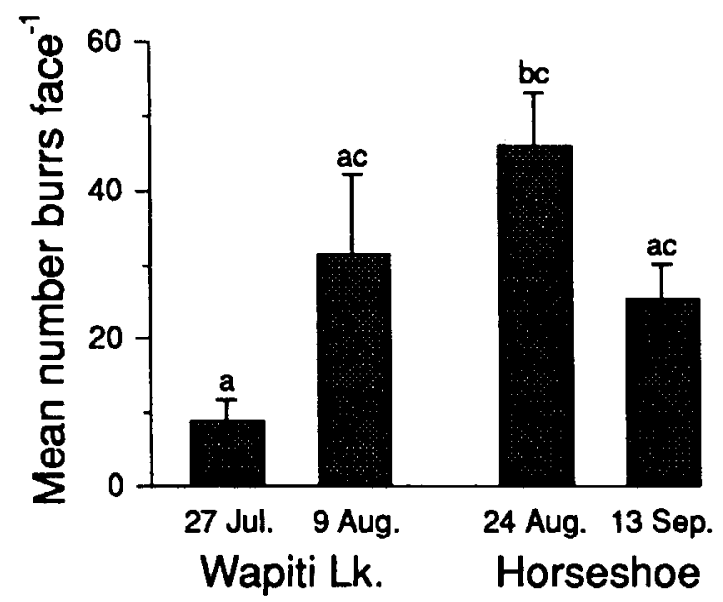

Fig. 3. Mean burr gains and losses on the faces of cows photographed every 2 weeks on 2 consecutive paddocks (Wapiti Lk. and Horseshoe) in a rotation. Cattle were moved on 19 August. Vertical bars indicate SE of the mean. Bars with different letters are significantly different at $\mathbf{p}<\mathbf{0 . 0 5}$.

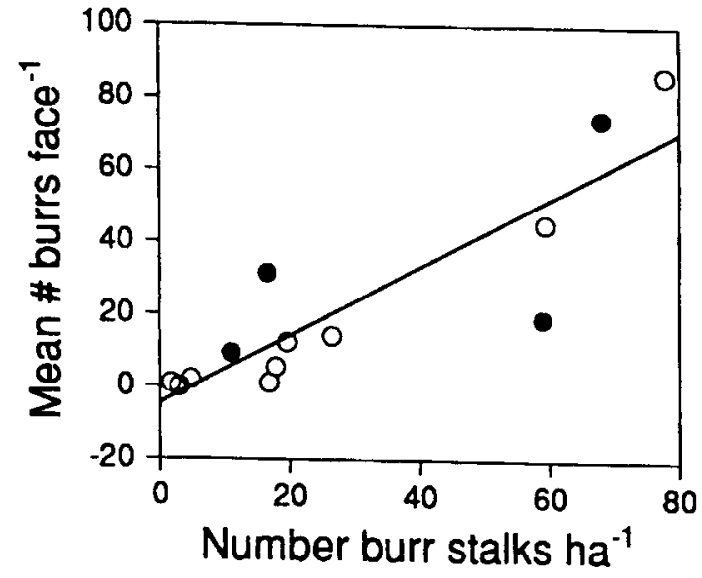

Fig. 4. Relationship between the mean number of burrs cow face ${ }^{-1}$ and the number of hound's-tongue burr stalks ha' ${ }^{-1}$. Filled circles depict cattle that were photographed in-situ on paddocks. Open circles depict cattle that were photographed immediately after round-up, when being moved to another paddock in their rotation. Regression through all circles (line shown), $Y=0.945 X-4.568$, $R^{2}=0.773, p<0.001, n=13$. Regression through open circles, $Y=1.067 X-8.379, R^{2}=0.929, p<0.001, n=9$.

Boorman and Fuller 1984). Furthermore, if cattle with burrs are transported any distance to market, the weed may spread much further than from paddock to paddock within a range unit.

Wildlife, such as deer and elk, also may contribute to hound'stongue seed dispersal, although it is suspected that their role as dispersers is minor relative to that of cattle. In the experiment investigating the loss of ripe burrs from hound's-tongue stalks in paddocks, few burrs were lost from the tagged stalks of the control paddock in 1994 (Fig. 1), despite fresh signs that deer had gone through the hound's-tongue patch. However, there also was evidence of minimal livestock activity, possibly due to the presence of stray cattle. Hence, final conclusions on the role of wildlife as hound's-tongue dispersers cannot be made without further study.

Further investigation also is required of the role of cattle in acquiring hound's-tongue seed if generalizations are to be made for a broader geographic area, and different management regimes. Despite the fact that only 1 location in each of 1993 and 1994 was used for study of catle acquisition of burs, similar results were obtained involving 2 different range units (Fig. 1). Cattle definitely were involved in acquiring a large percentage of the burrs produced by hound's-tongue plants on the paddocks where they had grazed. Stock density probably is another factor affecting the movement of burrs between sites, and should be included in further studies.

An understanding of the role of cattle in dispersing hound'stongue seed on rangelands together with information on the weed's ecological requirements, may be important in curtailing the spread of hound's-tongue to new areas. European studies indicate that hound's-tongue requires ground disturbance to become established (Boorman and Fuller 1984, Klinkhamer and De Jong 1988). In the interior of B.C., hound's-tongue grows particularly well on logged sites which become paddocks for cattle (Upadhyaya and Cranston 1991). Hence, cattle not only pick up burrs from previously-logged sites with dense stands of hound's- 


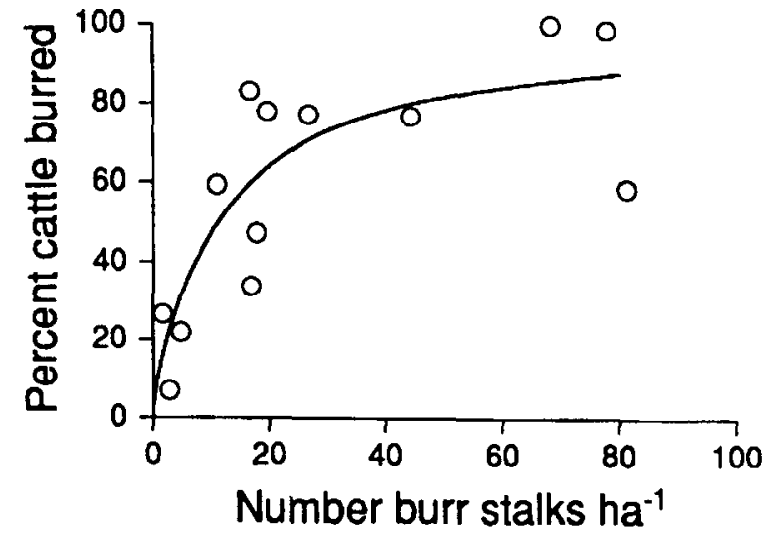

Fig. 5. Relationship between percent photographed cattle with burrs on their faces and number of burr stalks ha-1 of grazed paddock. The curve is described by the hyperbolic equation, \% cattle with burrs $=99.3 x /(11.0+x)$, where " $x "=$ number of burr stalks ha" . $\mathbf{R}^{2}=\mathbf{0 . 8 2 8}$.

tongue, but then introduce the seed to the recently disturbed sites of new paddocks. Cleaning cattle before they are moved to new paddocks or range units would help prevent or slow the spread and increase of this noxious weed.

There was a relationship between the numbers of burrs on cattle and the size of hound's-tongue infestations on paddocks. When cattle were on paddocks with low amounts of hound'stongue, the cattle had low numbers of burrs on their faces. Conversely, cattle that came off of paddocks with large amounts of hound's-tongue, tended to have high numbers of burrs. Subsequent investigation of the relationship between burr numbers on cattle and burr stalk densities on paddocks indicated that a positive, linear relationship exists (Fig. 4). Furthermore, the strength of the relationship was greater if the regression only included data from cattle photographed soon after being moved off of a paddock versus those photographed while still in a paddock. A possible explanation for this phenomenon is that during a round-up cattle are typically exposed to a large area of paddock in a short period of time, and tend to be moved down the trails and roads where hound's-tongue occurs. Hence, the burrs gained after a cattle move would be a better reflection of hound's-tongue density over a large part of the paddock. Further information on exposure time of cattle to hound's-tongue is required to fully understand the relationship between burr numbers on cattle and stalk densities.

The relationship between burrs on cattle and hound's-tongue density on paddocks could be of potential use in monitoring hound's-tongue infestations. The measurement of burrs, either through photography or recording the percent of burred cattle, would be a much easier and less time-consuming method of determining the density of hound's-tongue on paddocks than actually counting stalks or plants. The data obtained could then be used to estimate the impact of various controls, including biocontrol, on either stalk density or burr numbers on cattle, or to potentially determine the rate of spread of the weed. Further research is needed, however, to refine the relationships among these methods and the actual measures of hound's-tongue populations.

\section{Literature Cited}

Baker, D.C., R.A. Smart, M. Ralphs, and R.J. Molyneux. 1989. Hound's-tongue (Cynoglossum officinale) poisoning in a calf. J. Amer. Vet. Med. Assoc. 194:929-930.

Boorman, L.A., and R.M. Fuller. 1984. The comparative ecology of two sand dune biennials: Lactuca virosa $\mathrm{L}$. and Cynoglossum officinale L. New Phytol. 96:609-629.

De Jong, T.J. and P.G.L. Klinkhamer. 1988. Population ecology of the biennials Cirsium vulgare and Cynoglossum officinale in a coastal sand-dune area. J. Ecol. 76:366-382.

Klinkhamer, P.G.L. and T.J. De Jong. 1988. The importance of smallscale disturbance for seedling establishment in Cirsium vulgare and Cynoglossum officinale. J. Ecol. 76:383-392.

Knight, A.P., C.V. Kimberling, F.R. Stermitz, and M.R. Roby. 1984. Cynoglossum officinale (hound's-tongue)-A cause of pyrrolizidine alkaloid poisoning in horses. J. Amer. Vet. Med. Assoc. 184:647-650.

Pcnonlin. 1992. Version 4.0. SCI Software. Lexington, Ky.

Scoggan, H.J. 1978. The flora of Canada. Part 4. Dicotyledonae (Loasaceae to Compositae). Nat. Museum of Natur. Sci., Nat. Museums of Canada, Ottawa, Ont. pp. 1282-1283.

Systat. 1992. Systat for Windows: Statistics, Version 5 Edition. Evanston, Ill.

Upadhyaya, M.K. and R.S. Cranston. 1991. Distribution, biology, and control of hound's-tongue in British Columbia. Rangel. 13:103-106.

Upadhyaya, M.K., H.R. Tilsner, and M.D. Pitt. 1988. The biology of Canadian weeds. 87. Cynoglossum officinale L. Can. J. Plant Sci. 68:763-774.

Van der Meijden, E., P.G.L. Klinkhamer, T.J. De Jong, and C.A.M. Van Wijk. 1992. Meta-population dynamics of biennial plants: how to exploit temporary habitats. Acta Bot. Neerl. 41:249-270.

Van Leeuwen, B.H. and A.M.M. Van Breemen. 1980. Similarities and differences in some biennials. Acta Bot. Ncerl. 29:209-210. 